
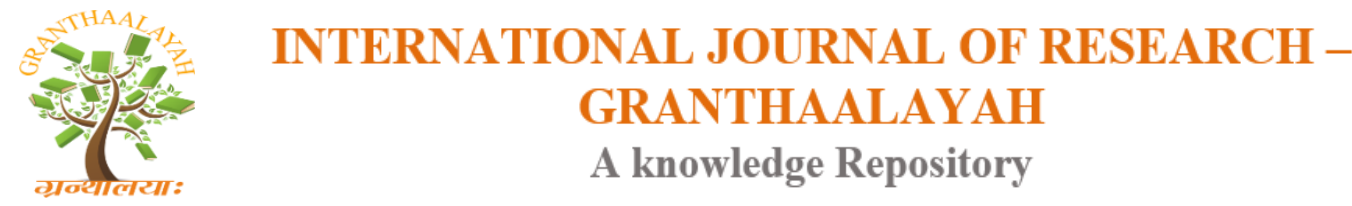

Management

\title{
AN EMPIRICAL STUDY OF TOTAL QUALITY MANAGEMENT ACCOUNTING IN HIGHER EDUCATION: STUDENTS AS CUSTOMERS PERSPECTIVE
}

\author{
Palak Kakkar *1 \\ ${ }^{* 1}$ Research Scholar, Department of Commerce, Delhi School of Economics, University of Delhi, \\ New Delhi, India
}

\begin{abstract}
With increased globalisation and competitiveness in the markets, the firms are in consistent search for new methods to satisfy their customers. The concept of TQM renders useful insight to achieve the said objective. Moreover, the concept is multi-disciplinary and is well suited to the Indian concept as well. Higher Education is an important sector that needs to cater to the need of quality education in the wake of plethora of options available to the students worldwide and also to satisfy the Accredition and assessment needs by agencies like NAAC. Thus, an attempt has been made to study the impact of Total Quality Management accounting in the Higher Education Sector. The paper has been divided into seven parts. While the first and second part deals with the introduction and conceptual framework respectively, the third part focuses on the various concepts of research methodology. The results of the empirical study have been reported in the fourth part. The fifth part deals with the suggestions for the policy makers followed by the research gaps so identified. The last part deals with the conclusion.
\end{abstract}

Keywords: Total Quality Management Accounting; Higher Education; Service Quality; Students as Customers Perspective.

Cite This Article: Palak Kakkar. (2017). “AN EMPIRICAL STUDY OF TOTAL QUALITY MANAGEMENT ACCOUNTING IN HIGHER EDUCATION: STUDENTS AS CUSTOMERS PERSPECTIVE." International Journal of Research - Granthaalayah, 5(7), 520-529. https://doi.org/10.29121/granthaalayah.v5.i7.2017.2160.

\section{Introduction}

In this highly competitive world, it has become imperative for the organisations to provide the best to their customers. However, it may be difficult to define what may be termed as the 'best'. Thus the firms are on a persistent search for new means which may help them serve the best. Undoubtedly, ensuring 'quality' across the value chain is one of the important factors for being successful on this path of being the best. The concept of Total Quality Management (TQM) offers useful inputs in this regard. 
Although TQM as a concept is not a new one. Infact it is one of the oldest concepts in the history of management. However, it still holds value even today as customers are in a hunt for quality. This can be substantiated from the fact that the organisations that adopted it have experienced a rise in their top line and bottom line values on account of reduced wastages, increased customer satisfaction, employee satisfaction, and quality improvement. Accordingly, its importance was felt in the Higher Education also.

In the Indian context also, the need for TQM Accounting in Higher Education cannot be ignored especially in the wake of cut-throat competition among universities, accreditions by various authorities like NAAC and the plethora of courses available to students to choose from. Indeed, the students may be considered not less than customers. Thus, even in Higher Education, TQM needs to be adopted as a customer-driven approach.

\section{Conceptual Framework}

Before diving into the concept of TQM Accounting in the field of Higher Education, it becomes imperative to first understand what constitutes TQM.

The International Organization for Standardization (ISO) has defined Quality as "degree to which a set of inherent characteristics fulfils requirements." In other words quality may be defined as the level to which a product or service is able to satisfy the needs of customers, organization and other interested parties by means of those features that form an inherent part of the product and are responsible to achieve satisfaction. For example: Incase of a Higher Education, quality would mean the degree to which its inherent characteristics like Curriculum , Course delivery, technological and infrastructural availability fulfils the requirement of students, employers and other stakeholders.

Since the term Quality is perceived differently by different people, the term Total Quality Management (TQM) has also been defined in a number of ways. However, a few common characteristics may be enlisted on the basis of extensive literature review. Some of them are as follows:

- People driven

- Process Orientation.

- Continuous improvements.

- Teamwork.

- Systems approach.

As far as Quality in Higher Education is concerned, Quality Assurance Agency for Higher Education, UK, defines Academic quality as- "Academic Quality is a way of describing how well the learning opportunities available to students help them in achieving their award. It is about making sure that appropriate and effective teaching, support, assessment and learning opportunities are provided for them."

Undoubtedly, TQM as a concept can be applied to any field or discipline. Thus, there is no proper definition of the term TQM Accounting. Thus, an attempt has been made to describe 
TQM Accounting in the study as the process of recording and presenting the various costs and benefits associated with adopting various TQM processes across the value chain.

Considering the cost associated with implementation of TQM or what may be called as Cost of ensuring Quality i.e., the sum of costs incurred by the company in preventing poor quality, in ensuring that the requirements are met, and any other costs incurred as a result of poor quality products, the following may be considered:

- PREVENTION COST- cost of activities designed to prevent poor quality in goods and services.(Training Staff in using Student Information System)

- APPRAISAL COST- costs incurred to ensure products and services confirm quality standards.(Monitoring students' experience using feedbacks)

- INTERNAL FAILURE COST - cost resulting from products or services not confirming to customer's requirement but which occur prior to its delivery to the customer.(Destroying letters or wrong information before it is circulated among students)

- EXTERNAL FAILURE COST- cost resulting from products or services not confirming to customer's needs but which occur after delivery to the customer. (Reorganising cancelled classes or rectifying poor quality teaching sessions.)

Prevention costs and appraisal costs are called conformance costs. Internal failure costs and external failure costs are called non-conformance costs.

Other costs would include:

- CUSTOMER INCURRED COSTS: Costs incurred by the customer in availing the goods and services. (Cost incurred in travelling for a class that stands cancelled without appropriate confirmation.)

- CUSTOMER DISSATISFACTION COST: Costs incurred by the customer in availing the goods and services but it does not meet their expectations. (Student feels that quality of lecture is not satisfactory or curriculum is outdated)

- LOSS OF REPUTATION COSTS: Costs incurred in improving the reputation lost on account of providing inadequate services.(Students spread bad word of mouth about the College on being dissatisfied by the quality of services offered.)

- LOST OPPORTUNITY COSTS: Costs incurred on losing out on various opportunities because of poor quality. (Losing out on grants due to poor performance or lack of good placements for students because of poor experience of employers).

As far as the benefits are concerned, TQM Accounting yields the following benefits:

- Assists the Management in taking various strategic and pricing decisions.

- Helps to judge the efficiency of the TQM program of the organisation.

- Ensures the interest of all the stakeholders

- Adds to the goodwill.

- Ensures legal compliance to safety standards

- Reduces the number of defects or reworks.

- Reduces costs across the value chain.

- Leads to increased customer satisfaction or reduction in the number of complaints.

- Increases the motivation levels of the staff as all the levels of management are involved in its implementation. 
- May even chalk out a way to achieve international recognition.

After all, as per Crosby (1992):“QUALITY IS FREE.”

Since the objective of the study essentially involves assessing whether TQM has been adopted in the Institution and the various TQM activities in the organization, measuring the various costs and benefits of such activities in financial terms, recording and classifying such activities and presenting the above to the concerned managerial authorities to assist them in decision making with students as a 'customer' perspective, it becomes important to first understand what studies say about students being considered as customers.

The logic that past studies give for adopting the students as 'customers' approach includes:

- Students pay heavy fees for their education as customers pay to buy products and services

- Like Customers, they also expect good grades irrespective of their efforts.

- They also shop for easiest programs and ready to 'mug up' study material.

- Like customers, spread word of mouth publicity about the Institution.

- May give critical reviews to demanding instructors, just like customers do.

However, there are a number of studies that are not in favour of considering students as customers due to the following reasons:

- Unlike customers, students do not pay the complete fees as it generally subsidized.

- Students cannot purchase a qualification. They have to put their efforts to earn rewards.

- Unlike customers, students are not aware of the 'best product' at this stage of their lives.

- Unlike the customers, they are not the 'only' stakeholders to be taken care of as there are others too which includes Faculty, Management, Employers, Agencies like NAAC, UGC and AICTE and the society at large.

- Their reviews may be biased due to other external factors.

Thus studies show that there are a number of methods that have been followed to account for TQM Accounting. Some of them are:

- Goal and specification Model

- Resource-input model

- Process model

- Satisfaction model

- Legitimacy model

- Absence of problems model

- Organizational Learning model

- Service quality (SERVQUAL)

- Service performance (SERVPERF)

- Higher Education performance (HEPerf)

- EduQUAL 


\section{Research Methodology}

\section{Research Objectives}

- To study the Construct of TQM.

- To study the factors required for successful implementation of TQM in HEI.

- To study the costs and benefits associated with TQM implementation in HEI.

- To study what TQM means to students of HEI and how relevant the concept is to their all round development.

- To study the impact of students' perception of the Institution's TQM implementation on the reputation and image of the Institution.

- To study whether TQM implementation can help Institution in earning higher ratings and accreditions from National agencies.

\section{Hypothesis of the Study}

- HO1- The factors identified do not predict TQM implementation in HEI.

- HO2- There is no significant difference between the mean values of the perception of actual delivery and expectation of delivery.

- HO3- There is no significant influence of academic Curriculum on the students' perception of actual service delivered by HEI.

- HO4- The students' perception gap are not correlated

\section{Type of Research}

This research is an exploratory process to find out the need for TQM Accounting in HEI and what the related costs and benefits of its implementation.

\section{Methodology Used}

- Survey Methodology and Purposive Non-Probability Convenience Sampling Method are employed for collection of data.

- Online survey were administered to the Commerce students of one of the College of North Campus, University of Delhi as the objective of the study is to get bird's eye view of students' perception of quality and how much successful their Institution has been in meeting up their expectations of quality.

\section{Type of Data}

- The Primary data so collected for empirical analysis was basically qualitative in nature.

- 93 responses were received from the Second and Third Year students of Commerce Department of one of the prestigious Colleges of Delhi University.

\section{Results of the Study}

A survey was conducted wherein a Questionnaire was administered to the students and their viewpoints were taken into consideration. The Questionnaire created using Google form containing 33 questions was administered. The students were asked to throw light on their expectations and actual perception of delivery of services offered by their College and their views about their academic Course and Curriculum being followed. The students were urged to express their views on a five point scale ranging from strongly disagree (-2) to strongly agree (2). 
Thus, SERVQUAL (Service Quality) method was used to identify the gap by determining the difference between mean perception of actual delivery and mean expectations of actual delivery. The results have been tabulated as follows:

\begin{tabular}{|l|l|l|l|}
\hline \multicolumn{1}{|c|}{ Question } & \multicolumn{1}{|c|}{$\begin{array}{c}\text { Mean } \\
\text { Perception }\end{array}$} & $\begin{array}{c}\text { Mean } \\
\text { Expctations }\end{array}$ & Gap \\
\hline $\begin{array}{l}\text { The Student Information System of the College is clear and } \\
\text { precise. }\end{array}$ & 0.58 & 0.75 & $-\mathbf{0 . 1 7}$ \\
\hline $\begin{array}{l}\text { The College has adequate infrastructural and administrative } \\
\text { facilities }\end{array}$ & 0.53 & 0.83 & $\mathbf{- 0 . 3 0}$ \\
\hline $\begin{array}{l}\text { The College has an adequate Fees structure. } \\
\text { The college is sensitive to social and environmental needs }\end{array}$ & 0.92 & 1.35 & $\mathbf{- 0 . 0 3}$ \\
\hline $\begin{array}{l}\text { The College adheres to its schedule and effectively uses my } \\
\text { time. }\end{array}$ & 0.31 & 0.58 & $-\mathbf{0 . 1 1}$ \\
\hline $\begin{array}{l}\text { The College offers facilities for Personality } \\
\text { Development. }\end{array}$ & 0.45 & 0.73 & $\mathbf{- 0 . 2 7}$ \\
\hline $\begin{array}{l}\text { There is career orientation among parents, educators, and } \\
\text { students by the College. }\end{array}$ & 0.22 & 0.46 & $\mathbf{- 0 . 2 8}$ \\
\hline $\begin{array}{l}\text { The College provides for a medium to communicate with } \\
\text { Seniors' and Alumni. }\end{array}$ & 0.19 & 0.46 & $\mathbf{- 0 . 2 4}$ \\
\hline $\begin{array}{l}\text { The college has an effective Compliant Redressal } \\
\text { Procedure. }\end{array}$ & 0.17 & 0.52 & $\mathbf{- 0 . 2 7}$ \\
\hline
\end{tabular}

Accordingly, an attempt has been made to find out whether any relationship exists between Perception of actual delivery and overall Quality gap.

Thus, Excel was used to find out the above relationship. Correlation was found between the different values of students' Perception about various aspects of Service quality that has been delivered by the College and the gap was so identified.

\begin{tabular}{|l|c|}
\hline \multicolumn{1}{|c|}{ Question } & Correlation Coefficient \\
\hline The Student Information System of the College is clear and precise. & 0.39 \\
\hline The College has adequate infrastructural and administrative & 0.36 \\
\hline The College has an adequate Fees structure. & 0.40 \\
\hline The college is sensitive to social and environmental needs & 0.28 \\
\hline The College adheres to its schedule and effectively uses my time. & 0.31 \\
\hline $\begin{array}{l}\text { The College offers facilities for Personality Development. } \\
\text { There is career orientation among parents, educators, and } \\
\text { students by the College. }\end{array}$ & 0.43 \\
\hline $\begin{array}{l}\text { The College provides for a medium to communicate with Seniors'and } \\
\text { Alumni. }\end{array}$ & 0.39 \\
\hline The college has an effective Compliant Redressal Procedure. & 0.44 \\
\hline
\end{tabular}

The overall Correlation Coefficient was found as 0.90 


\section{Academic Course and its Delivery}

Students' perception about the relevance of their Academic Course, the Curriculum being followed and the way it is delivered may have a great impact on their perception about the overall quality services delivered by the institution. This area has therefore, being specifically included because of its heightened importance in determining Service Gaps.

\begin{tabular}{|c|c|c|}
\hline QUESTION & Mean values & Standard \\
\hline My Curriculum is up-to-date and caters to future needs. & 0.52 & 0.94 \\
\hline My curriculum allows for future research. & 0.37 & 0.94 \\
\hline $\begin{array}{l}\text { The Academic Staff is professionally experienced and is } \\
\text { readily available for help. }\end{array}$ & 0.71 & 0.92 \\
\hline $\begin{array}{l}\text { I am satisfied with the quality of lectures delivered and the } \\
\text { teaching methods adopted }\end{array}$ & 0.42 & 0.99 \\
\hline I am satisfied with the Student-Teacher Ratio. & 0.53 & 0.96 \\
\hline I am satisfied with the machinery for evaluation & 0.18 & 0.97 \\
\hline $\begin{array}{l}\text { The College organizes Industrial Visits and has links with } \\
\text { business environment. }\end{array}$ & -0.06 & 0.93 \\
\hline $\begin{array}{l}\text { My feedback matters to the college and helps to improve } \\
\text { instruction. }\end{array}$ & 0.58 & 1.07 \\
\hline I am satisfied with the regularity and timing of the feedback. & 0.34 & 1.02 \\
\hline The instruments used in the feedback are adequate. & 0.53 & 0.97 \\
\hline
\end{tabular}

\section{Suggestions for Policy Makers}

- Clearly laid down instructions about the relevant contact persons and relevant directions should clearly mentioned at the various points of the institution itself.

- An institution's infrastructure acts as one of the attractive points. A student comes to College not only to attend classes but to avail facilities of Computer labs, library, gymnasium and other sports facilities. Thus, an institution must ensure adequate infrastructural and administrative facilities for its students.

- An efficient fees structure is one of the most important aspects. Since most of the colleges are funded by the Government, especially in India, the benefit must accrue to the students. In our study, since the lowest gap is found for the adequate fee structure systems, it is suggested that the college continues with the same system and even try to improve the value for money for students by providing more facilities and opportunities to the students for the same fee structure.

- Quality is multi-dimensional and is viewed from an overall perspective. This study found a very small gap in terms of their Institution's responsiveness to social and environmental needs. It is highly suggested that the college takes up such initiatives to sensitize the students also.

- Students pay for their education not only in terms of money but also the time they spend for the same. It must be ensured that effective scheduling of lectures is done so that minimum time is wasted in between the lectures. 
- The Institutions must provide a mechanism for the overall personality development by creating facilities for add-on courses, organizing industrial visits and talks, encouraging innovative projects and instilling entrepreneurial capabilities among students.

- It is suggested that Institutions organise orientation programs for students where they are given a chance to interact with experts, offer internships where they can better understand different types of career options available and encourage students to innovate and begin their startups.

- Undoubtedly, what students hear from the world outside adds to their level of expectations. Thus, an effective medium should be created by the Institutions wherein the alumni can come and share their experiences with the existing students. This helps the students build realistic expectations from the Institutions.

Moreover, it should not be a cumbersome job for the students to register and track the status of their complaints. In our study, since a high quality gap was found in the complaint redressal mechanism, it is suggested to the college comes up with easy means for students to register their complaints

As far as the academic courses are concerned:

- It is suggested that the department provides for more industrial visits and make students aware of the college's various initiatives to collaborate with various business Enterprises. This would not only leads to the up gradation of students but will also make them feel that the college is taking up initiatives to create balance between classroom and out of the classroom study.

- Since the students are highly satisfied with the Academic Staff and their professional experiences it is suggested that the college continues with such measures to maintain and upgrade the same.

- Since the deviation was found to be high about their expectation about how much valuable their feedback is to their College, it is suggested that College intelligently makes use of such feedback. There is a need to build trust in the minds of students so that they give a genuine feedback and the concept is not left as a victim of 'grade inflation'.

\section{A Few Research Gaps}

A lot of scope for research is seen in the area of:

- Since the data has been collected for a single period and that too from a single Institution, scope may be seen in terms of research on the basis of panel data.

- Development of framework that can conduct a cost-benefit analysis of TQM accounting.

- Measures for developing a suitable basis of determining the various aspects of quality and the financial performance.

- Developing accounting software's compatible with TQM Accounting.

- In the absence of any accounting standard on TQM Accounting in India, an attempt can be made in making policy recommendations in this direction. This will ensure availability of more information to the various interested parties for their decision making. Even the customers will be able to avail more information on quality processes undertaken by their service providers and can accordingly make their healthy purchases. 
Also, with increasing role of corporate social responsibility accounting and environmental accounting, an attempt can made to link the benefits of TQM to these aspects. This would surely add to the goodwill and they can simultaneously target so many aspects at the same time.

\section{Conclusion}

- Adopting a TQM accounting program brings along a number of benefits. It assists the Management in taking various strategic and pricing decisions. Moreover, a pre and post Accredition study may also be conducted to look for the difference in quality, if any.

- Implementation of a system that can account for the cost of quality is equally important. Four costs of ensuring quality have been described in the literature-Prevention cost, Appraisal cost, internal failure cost and External failure cost.

- The impact of earning recognition for TQM implementation surely increases the motivation levels of the staff and adds to the goodwill. This holds immense importance in view of the various opportunities available to Institutions earning high grades from Accredition agencies. But there is no surety that a rank holder will perform consistently better in the future. Also, there is no consensus about what constitutes the basic characteristics of a rank holder.

- Since TQM is multi-dimensional and qualitative in nature, assigning a monetary value to it is a pretty difficult task. Also, there is no clear basis or parameter for assigning such value. Thus, it totally depends upon the discretion of the Accountant to select a suitable basis depending upon the conditions in the environment. However, an intervention is sought from governmental authorities in this regard.

\section{References}

[1] Boonlert Watjatrakul , (2014),"FACTORS AFFECTING STUDENTS' INTENTIONS TO STUDY AT UNIVERSITIES ADOPTING THE "STUDENT-AS-CUSTOMER" CONCEPT", International Journal of Educational Management, Vol. 28 Iss 6

[2] Brenda M. OldfieldSteve Baron, (2000),"STUDENT PERCEPTIONS OF SERVICE QUALITY IN A UK UNIVERSITY BUSINESS AND MANAGEMENT FACULTY" Crosby, P. 1992. "QUALITY IS FREE", New York, McGraw-Hill.

[3] Deming, W.E. 1991. "A SEMINAL THINKER TAKES A DETAILED LOOK AT THE QUALITY ”, Automobile Magazine, October : 106-11.

[4] George A. Boyne and Richard M. Walker, "TOTAL QUALITY MANAGEMENT AND PERFORMANCE: AN EVALUATION OF THE EVIDENCE AND LESSONS FOR RESEARCH ON PUBLIC ORGANIZATIONS", Public Performance \& Management Review, Vol. 26, No. 2 (Dec., 2002), pp. 111-131

[5] John Rallis, "MANAGEMENT ACCOUNTING AND TOTAL QUALITY MANAGEMENT , RECENT TECHNIQUES IN EDUCATIONAL SCIENCES".

[6] Lynne Eagle Ross Brennan, (2007),"ARE STUDENTS CUSTOMERS? TQM AND MARKETING PERSPECTIVES", Quality Assurance in Education, Vol. 15 Iss 1

[7] Marilyn M. Helms Ashley B. Williams Judy C. Nixon, (2001),"TQM PRINCIPLES AND THEIR RELEVANCE TO HIGHER EDUCATION: THE QUESTION OF TENURE AND POSTTENURE REVIEW", International Journal of Educational Management, Vol. 15 Iss 7

[8] Mark Glaser, (1993) "RECONCILIATION OF TOTAL QUALITY MANAGEMENT AND TRADITIONAL PERFORMANCE IMPROVEMENT TOOLS”, Public Productivity \& 
Management Review, Vol. 16, No. 4, Fiscal Pressures and Productive Solutions: Proceedings of the Fifth National Public Sector Productivity Conference (Summer, 1993), pp. 379-386

[9] Maureen Tam (2001) Measuring Quality and Performance in Higher Education, Quality in Higher Education, 7:1, 47-54

[10] Mohammad A. Ashraf Abu Zafar Rashed Osman Sarker Rafij Ahmed Ratan , (2016),"DETERMINANTS OF QUALITY EDUCATION IN PRIVATE UNIVERSITIES FROM STUDENT PERSPECTIVES", Quality Assurance in Education, Vol. 24 Iss 1

[11] N. Senthilkumar A. Arulraj, (2011),"SQM-HEI - DETERMINATION OF SERVICE QUALITY MEASUREMENT OF HIGHER EDUCATION IN INDIA", Journal of Modelling in Management, Vol. 6 Iss 1.

[12] Parmjit Kaur, "CURRENT COST OF QUALITY MANAGEMENT PRACTICES IN INDIA IN THE ERA OF GLOBALIZATION: AN EMPIRICAL STUDY OF SELECTED COMPANIES”, Decision, Vol. 36, No.1, April, 2009

[13] Romadhani Ardi Akhmad Hidayatno Teuku Yuri M. Zagloel, (2012),"INVESTIGATING RELATIONSHIPS AMONG QUALITY DIMENSIONS IN HIGHER EDUCATION", Quality Assurance in Education, Vol. 20

[14] Sangeeta Sahney, (2016),"USE OF MULTIPLE METHODOLOGIES FOR DEVELOPING A CUSTOMER-ORIENTED MODEL OF TOTAL QUALITY MANAGEMENT IN HIGHER EDUCATION", International Journal of Educational Management, Vol. 30 Iss 3

\footnotetext{
*Corresponding author.

E-mail address: palak.kakkar18@ gmail.com
} 